Cómo citar este trabajo: Alberdi Collantes, J. C. (2018). El paisaje atlántico vasco ante la marginalización ganadera: claves para su conservación. Boletín de la Asociación de Geógrafos Españoles, 80, 2605, 1-32. http://dx.doi.org/10.21138/bage.2605

\title{
El paisaje atlántico vasco ante la marginalización ganadera: claves para su conservación
}

\author{
The Basque Atlantic landscape in the face of livestock marginalization: \\ keys to its conservation
}

\author{
Juan Cruz Alberdi Collantes \\ juancruz.alberdi@ehu.eus \\ Departamento de Geografía, Prehistoria y Arqueología \\ Universidad del País Vasco (España)
}

\section{Resumen}

La investigación parte de la premisa de que una abandono de las funciones ganaderas originaria una reacción similar en los usos del suelo, siendo el paisaje de campiña atlántica el principal afectado. La metodología se centra en el estudio de casos y en la entrevista, como medios para completar y cualificar la información oficial. Los resultados muestran que el abandono ganadero es, si cabe, mayor que el esperado pero, en apariencia, los usos del suelo apenas se alteran. Se analizan las causas, a menudo no productivas, que explican esta situación y se concluye que es una situación transitoria. Las acciones propuestas que pudieran frenar este proceso tan sólo amortiguarán el escenario previsto, la pérdida del paisaje atlántico de buena parte del País Vasco.

Palabras clave: uso de la tierra; tierra agrícola; ganadería; agricultura; paisaje.

\begin{abstract}
The research is based on the premise that abandonment of livestock functions originates a similar reaction in land use, with the Atlantic landscape being the main affected. The methodology focuses on local cases and interviews, as means to complete and qualify official information. The results show that livestock abandonment is more important than expected, but, apparently, the land uses are barely altered. The causes that lead to this situation are analyzed (especially non productive
\end{abstract}


causes) and it is concluded that it is a transitory situation. Again this scenery the proposed actions will only cushion the foreseen situation, the loss of the Atlantic landscape in non machinery areas of the Basque Country.

Key words: land use; agricultural land; livestock; agriculture; landscape.

\section{Subexplotación frente abandono: introducción al objeto de la investigación}

La retirada de la actividad agraria por parte de un alto número de explotaciones es una realidad extendida ya a todas las regiones europeas, generando un proceso complejo en el que influyen condicionantes físicos, sociales, económicos e incluso de la política agraria bajo la cual se desenvuelve la actividad agropecuaria y forestal.

Atendiendo a sus consecuencias paisajísticas, existe el consenso científico de que el abandono de tierras se manifiesta de distinta forma dependiente de su especialización productiva y de sus estructuras agrarias. En España, por ejemplo, el fenómeno de abandono presenta características diferentes entre las zonas de vocación agrícola y ganadera e incluso entre estas últimas también se observan situaciones diferenciadas

Mientras en aquellos espacios de montaña, alejados de espacios urbanos, y que sufrieron una despoblación y abandono intensos hace varias décadas, es el bosque el que ha ocupado buena parte de los antiguos pastizales, en los entornos en los que el paisaje de prados es prioritario, el propietario se resiste a su matorralización e inicia estrategias que permitan mantener en uso su heredad.

El último escenario reflejado, la subexplotación, parece ser, a priori, el que se plantea también en el área de estudio, la cornisa atlántica del País Vasco. Pero es una realidad por confirmar, no recogida aún en las estadísticas oficiales, en las que los usos del suelo parecen permanecer inmutables, ajenos a la progresiva reducción de su presión ganadera. En esta investigación recurrimos al estudio de casos, a la escala local, a la observación de la parcela e incluso a la entrevista para complementar la información oficial y verificar el escenario de infrautilización e incluso de seudomatorralización que a priori esperamos.

\section{La subexplotación del suelo agrario: definición, factores determinantes y problemas analíticos}

La pérdida de explotaciones y las alteraciones observadas en los aprovechamientos de los suelos agrarios debemos englobarlas en un proceso general, prolongado en el tiempo y que se va materializando con gran intensidad desde mediados de siglo. Este proceso está todavía lejos de finalizar o al menos así se desprende de las decisiones adoptadas desde las instituciones europeas (Malagón, 2012), en la que para los siguientes años observa la necesidad de continuar con la 
adecuación progresiva a las leyes del mercado y, como consecuencia, con el consecuente proceso de reestructuración.

La pérdida de activos es más visible en aquellas zonas en las que el desarrollo de la función agraria ha de afrontar dificultades físicas o humanas, como pueden ser las zonas de agricultura de montaña. Consecuencia de ello, esta tipología de unidad productiva no puede resistir ante el proceso económico desatado a partir de la liberalización de mercados y la globalización económica y entra en crisis (Cabaña et al., 2013).

Aparentemente, el cierre de explotaciones repercute en beneficio de otras que tienen ahora a su disposición las tierras que éstas ocupaban. Esta es una situación habitual en los entornos de montaña en los que dicha reestructuración apoya en un principio la consecución de una actividad más concentrada, tanto en producción como en suelos, pero también más eficiente. Los espacios menos productivos, de mayor pendiente o más alejados, se abandonan progresivamente mientras la actividad se concentra en el fondo de los valles. ${ }^{1}$

Dentro del escenario tradicional de la evolución de los usos del suelo las excepciones son cada vez más importantes y el abandono de suelos, incluso arables, ya no es exclusivo de zonas alejadas y de montaña. Aunque siguen siendo estas áreas las más afectadas, zonas con buenas condiciones agrológicas también se incorporan a este proceso (Hatna \& Bakker, 2011).

Los indicadores tradicionales de ruralidad (condiciones agrológicas adversas y pérdida de población preferentemente) ya no explican los procesos de abandono del uso agrario con claridad (Munteanu et al., 2014) y se observa que ya no existe un único patrón en los cambios de usos del medio rural Europeo. Es más, comienzan a apuntarse tipologías de regiones con comportamientos similares en función de razonamientos demográficos, económicos e incluso sociológicos diferentes (Verburg et al., 2010).

Una muestra de la diversidad de comportamientos apuntada parece observarse en muchas regiones de la Cornisa Cantábrica, que no responde claramente al proceso tradicional de abandono se suelo agrícola. Las investigaciones apuntan que muchas de las explotaciones que la teoría clasifica como inviables continúan en activo mucho más allá del período esperado (Corbero \& Crecente, 2008; Murua, 2012; Ruiz Urrestarazu \& Galdós, 2013ª). Las razones que explican este fenómeno son variadas. Entre ellas podemos señalar la transferencia de la titularidad a la pareja (cuando esta tiene menor edad), la búsqueda de otras fuentes de ingresos externos a la explotación (agricultura a tiempo parcial, por ejemplo), o la mera continuación de las actividades más allá de la edad de

1 Euromontana, la asociación europea multisectorial para la cooperación y el desarrollo de los territorios de montaña, aporta multitud de ejemplos que analizan la evolución de los usos agrarios consecuencia del progresivo abandono agrario en regiones de montaña (Euromotana, 1997). En el caso de las montaña española, Collantes (2005) estudia cómo se ha materializado este fenómeno a lo largo del siglo XX. 
jubilación (López Iglesias, 1996; Sineiro García et al., 2004). El poco tiempo disponible que deja el trabajo fuera de la explotación, o simplemente la edad, fuerzan al titular a realizar cambios en el modo en que maneja la explotación, transformándola hacia usos menos intensivos y, por lo tanto, menos exigentes en trabajo, o reestructurando la explotación, con disminución de las actividades en las menos productivas o accesibles (Baldock et al., 1996; Alberdi, 2002).

Las estrategias señaladas son indicadoras de un proceso que finaliza con el cese de la explotación (Mauleón, 1998). No obstante, este proceso puede prolongarse en el tiempo durante un período indeterminado, y en su transcurso el nivel de manejo de la totalidad o de parte de las tierras de la explotación se vuelve ocasional y con unos ingresos asociados casi nulos. Pero por persistir un cierto uso de la tierra esta no se encuentra estrictamente abandonada, y por este motivo la situación puede ser calificada como de abandono oculto o de semiabandono (Corbero \& Crecente, 2008). El abandono oculto, como se desprende de su nombre, no es fácil de identificar sobre el terreno por cuanto el crecimiento de la vegetación espontánea está controlado o limitado por la (escasa) actividad realizada.

La conexión entre marginalidad y abandono es clara, pues en caso de ajuste de la producción la tierra marginal es usualmente la primera en ser abandonada (Renwick et al, 2013). Pero lo cierto es que la realidad muestra que existen factores de otro tipo (Baldock et al., 1996; Hatna and Bakker, 2010; Van der Sluis et al, 2016) que también influyen en el carácter marginal de la tierra y, por lo tanto, en la localización territorial del abandono, como factores económicos relacionados con la viabilidad de la actividad, de tipo estructural e incluso sociológicos como la edad, ausencia de relevo generacional....

Es por ello que buena parte de las medidas de apoyo a la agricultura, de la Políitica Agraria Comunitaria (PAC), especialmente el denominado "pago único" hayan estado orientadas a mantener en uso el suelo agrario, aún a costa de promover su extensificación y subexplotación, con la condición de mantener las tierras agrarias en buenas condiciones agronómicas y ambientales (Mata, 2004)

El nuevo modelo de la PAC se encuentra regulado en el Reglamento (UE) n 1307/2013 del Parlamento Europeo y del Consejo de 17 de diciembre de 2013 de los Pagos Directos y ofrece algunas novedades que van a condicionar el futuro uso del suelo (Gil, 2015), especialmente la necesidad de ser agricultor activo. El objetivo principal de este nuevo requisito es conseguir que las ayudas de la PAC beneficien a aquellas explotaciones agrarias con una actividad real y, por lo tanto, que sólo aquellos agricultores que sean activos puedan beneficiarse de las ayudas. Su resultado dependerá de la aplicación que cada Comunidad realice de este criterio, siendo varios los investigadores que no ven cambios reseñables en la medida (Molinero et al., 2012). 
Desde las instituciones europeas y desde la PAC se ha ido priorizando la forestación de tierras agrarias que, debido a sus condiciones agrológicas o geográficas, presentaban menos posibilidades de mantener sus usos agrarios. Estos programas, mantenidos durante décadas, han posibilitado un incremento de la superficie forestal (Rojo et al, 2009; Keenleyside et al., 2010; Munteanu et al., 2014). Pero han sido muchos los espacios en los que estas medidas no han cuajado. Los espacios tradicionalmente agrícolas (Corbere \& Crecente, 2005), aquellas zonas próximas a núcleos urbanos de relevancia (Alberdi, 2002) y aquellas regiones en las que predominaba un aprovechamiento silvícola intensivo (Murua et al., 2012), entre otros, han sido una excepción.

La incidencia de otras medidas no lideradas por la PAC es mucho menor. En Europa funcionan actualmente diferentes iniciativas dirigidas a facilitar la puesta en producción de suelos agrícolas, desde la escala nacional a la local, fundamentadas principalmente en tierras de su propiedad (Klare \& Doll, 2000; Van Dijk \& Kopeva, 2006), originarias de nuevos suelos útiles, procedentes de sobrantes de concentración parcelaria o, por redistribución por parte del Estado de fincas a sus antiguos propietarios (Boliari, 2013). E incluso por iniciativas que se apoyan en cesiones por prejubilación, como el ejemplo de Asturias $^{2}$ y otros incluso anteriores, como en el caso Holandés (Van Den Brink, 1990). Su incidencia, sin embargo, es relativa y muy localizada, visible especialmente en los países del este de Europa.

Otra serie de medidas dirigidas a evitar la infrautilización o a poner en uso nuevos suelos agrarios, si atendemos a las aportaciones recogidas en la revisión bibliográfica, son muy reducidas y pasan de manera desapercibida. Es el caso de la utilización del fuego en zonas de montaña para potenciar el uso extensivo de los prados, común en algunas zonas del Pirineo vasco-francés, o, frente a la matorralización generalizada, de la utilización de la ganadería extensiva para evitar riesgos de incendio... (Varela-Redondo et al., 2007), pero en todos los casos su incidencia parece ser muy localizada.

Sobre los resultados obtenidos por la puesta en marcha de iniciativas tendentes a mantener el uso agrario del suelo las controversias son evidentes, aunque parece concluirse que estas ayudas contribuyen a mantener el paisaje de muchas zonas europeas, especialmente de aquellas dominadas por explotaciones familiares grandes y desarrolladas sobre suelos con condiciones agrarias propensas a su mecanización. En las áreas de montaña y en los piedemontes montañosos quedan muy pocas explotaciones, muy pocos profesionales $y$, aunque sobran pastos, hay muy

2 La potenciación de las prejubilaciones se convierte en uno de los medios más utilizados para distribuir tierras de agricultores que por edad van reduciendo su cabaña ganadera a otros que demandan más suelo. Son iniciativas apoyadas por la Políitica Agraria Comunitaria y cofinanciadas por las administraciones regionales. En España la iniciativa del Banco de Suelo de Asturias, referente estatal para el desarrollo de la agricultura, fundamenta su oferta de suelo en la promoción de las prejubilaciones, en la que el cesante cede su suelo a una entidad pública a cambio de acogerse a las ayudas de prejubilación (Maceda, 1996; Iglesias, 2010) 
poca gente dispuesta a vivir en las condiciones duras que exige la explotación agrícola y ganadera. Todas estas circunstancias tienen consecuencias demográficas, económicas y sociales, pero también paisajísticas, porque se ha producido un abandono generalizado de pastizales, de terrenos comunales y de tierras agrícolas que hoy no se labran, que han favorecido la matorralización y la extensión de los incendios como forma de combatirla (Molinero et al., 2012). Los pagos de la PAC no han contribuido a reducir el abandono agrario, no al menos en zonas de pastos y montaña (Renwick et al., 2013) y son muchas las investigaciones que reclaman un cambio en las medidas europeas, proponiendo una apuesta por políticas transversales centradas en el uso del suelo y en las peculiaridades locales (Hubet et al., 2013)

En las regiones cantábricas, sea por justificaciones económicas, políticas o sociales, el paisaje característico de prados verdes, bosquetes, aldeas y caseríos mantiene aparentemente su estado habitual (Murua et al., 2012). Muchos investigadores coinciden en el endeble equilibrio en el que se apoya y muchos son los que señalan los primeros síntomas que atestiguan un abandono que se presupone inevitable pero que, al menos por el momento, no llega. En este estadio apoyamos nuestra investigación, en la convicción de que la falta del elemento humano, el agricultor, y de un aprovechamiento, el pasto a siega o a diente, influirá, aun siéndolo a largo plazo, sobre el equilibrio y la calidad del paisaje de campiña atlántica.

\section{Objetivos y metodología: el recurso al análisis de casos}

El objeto de la investigación es el de corroborar la hipótesis de partida, que plantea que la situación actual, en la que el abandono de la actividad agroganadera no genera cambios significativos en el paisaje de campiña, es tan sólo un estadio transitorio. Justificar esta afirmación obliga a analizar y comprender las causas que explican el contexto actual para así abordar el escenario de cambio al que a medio-largo plazo se enfrentan los usos del suelo y, de considerarse oportuno, plantear medidas correctoras.

Para ello se parte de la afirmación de que el paisaje rural es en gran medida una manifestación territorial de la propia actividad agraria (Delgado et al., 2010). Tanto los elementos del paisaje como su organización y su propia evolución dependen de las estructuras agrarias, los sistemas y tipos de cultivo y la orientación productiva de las explotaciones. Cualquier modificación en estos últimos factores se trasluce en cambios paisajísticos.

El paisaje rural de los valles vasco-atlánticos, el paisaje del caserío vasco, mantiene una configuración sencilla, con cuatro elementos esenciales de su paisaje: la enmarañada topografía, la dispersión del hábitat, los prados y las coníferas, y un quinto elemento que influye de manera decisiva en su evolución: la inmediatez urbana. Todo ello da lugar a una estructura en mosaico de las laderas de los valles donde sus teselas principales son las parcelas de pinares, los prados, y en 
su caso, los rodales de bosque mixto atlántico. Este paisaje actual del caserío es una construcción relativamente reciente, un estado evolutivo más dentro de una larga trayectoria histórica que ofrece fases diversas acordes con la estructura socioeconómica dominante en cada momento. ${ }^{3}$ Su resultado, no exclusivo, es un caserío de orientación ganadera y forestal. La conjunción de ambas actividades da lugar al paisaje mixto de campiña atlántica (Ruiz Urrestarazu \& Galdós, 2013a).

La permanencia de este valioso paisaje sólo es posible si el caserío conserva su dedicación agraria y, más específicamente, ganadera. Conocer su equilibrio actual requiere responder a toda una serie de interrogantes, aspectos que estructuran la investigación y que resumimos en cuatro cuestiones:

- Grado de materialización del abandono agroganadero. Se ha de discernir si nos enfrentamos a una retirada generalizada o a una concentración de la actividad sin una reducción evidente de la carga ganadera.

- Repercusión del abandono agrario/concentración ganadera en los usos del suelo, visible previsiblemente a escala local o parcelaria.

- Justificación del equilibrio actual de los usos del suelo y estudio del interés por disfrutar de mayor base territorial por aquel que continua.

- Escenario de futuro, en función de variables económicas, posibilidades de mano de obra, u otras justificaciones (sociales, culturales...)

Respecto al método utilizado, la indagación es abordada recurriendo a diferentes escalas de estudio. Cada uno de los capítulos analizados se afronta en primer lugar a partir de fuentes estadísticas y cartográficas publicadas, a diferentes escalas, desde la regional a la municipal.

Pero, dada la rapidez con la que el proceso de abandono de la actividad ganadera se está materializando, es previsible que los resultados estadísticos no estén convenientemente actualizados y no sean capaces de detectar cambios a escalas aún más locales. Es por ello que en la investigación se procede a aplicar dos metodologías complementarias para completar o corregir la información estadística y publicada, como son:

- Estudios de casos: se recurre al análisis de la evolución del uso agrario en el parcelario de un entorno reducido, un barrio o un valle, abarcable desde una óptica visual humana, como método de análisis de la dinámica de determinados fenómenos.

3 Tal como ha sido descrito y explicado por numerosos investigadores (entre otros, Caro Baroja, 1971; Etxezarreta, 1977; Ainz, 2001; Ruiz Urrestarazu \& Galdós, 2005) 
- Entrevista: se apuesta por la entrevista individual semiestructurada como técnica capaz de ofrecer datos cuantitativos y el contraste cualitativo necesario sobre el devenir de los usos agrarios. ${ }^{4}$ Se entablan conversaciones con diferentes tipologías de agricultores en función de su producción y especialización, con miembros de la comunidad local y con agentes de desarrollo rural.

Toda la información obtenida es contrastada y comparada con las afirmaciones de investigaciones que por proximidad o por problemática han abordado la cuestión de las implicaciones del abandono agrario. El objetivo es el de situar el ejemplo vasco en un contexto global, resaltando las peculiaridades que éste pudiera presentar.

Una última cuestión a aclarar responde a la terminología utilizada en el análisis de los usos y aprovechamientos de los prados, que puede llevar a equívoco dada la diversidad de fuentes abordadas. En la investigación optamos por utilizar el nomenclátor básico de pastos de España, aprobado por la Sociedad Española para el Estudio de los Pastos (Ferrer et al., 2011). Partiendo del término genérico de pasto, como cualquier recurso vegetal que sirve de alimento al ganado bien en pastoreo o bien como forraje, subdivide los herbáceos en diferentes grupos, de los cuales tres tienen especial relevancia en este trabajo:

1. Prado: Comunidad vegetal espontánea densa y húmeda, siempre verde, producida por el hombre o la acción del pastoreo. Se puede aprovechar por siega o pastoreo indistintamente.

2. Pastizal: Comunidad natural dominada, en general, por especies bastas que, por efecto del clima, se seca o agosta en verano. Su densidad es variable y frecuentemente está salpicado de especies leñosas. Se aprovecha mediante pastoreo extensivo.

3. Pradera: Cultivo constituido fundamentalmente por gramíneas y leguminosas, que puede ser aprovechado por siega o pastoreo de forma indistinta. En general son plurianuales. Con el paso del tiempo pueden naturalizarse (las especies sembradas son sustituidas por espontáneas), transformándose en prados o pastizales, en función de la humedad.

Junto a estas definiciones, por influencia de la nomenclatura del censo agrario, se ha de a tener en cuenta la definición del término Superficie Agrícola Utilizada (SAU) como "El conjunto de la superficie de tierras labradas y tierras para pastos permanentes. Las tierras labradas comprenden los cultivos herbáceos, los barbechos, los huertos familiares y las tierras consagradas a cultivos leñosos. Tierras para pastos permanentes, son tierras dedicadas a la producción de hierba de forma permanente por un periodo de cinco años o más, que no se incluyen en la rotación de cultivos, tales como prados o praderas permanentes y otras superficies utilizadas para pastos. Se

4 Las diferentes tipologías de entrevistas cualificadas son ampliamente estudiadas por Guerrero (2001). Dentro de la categoría señalada agrega una subcategoría que también incorporamos en el estudio, la entrevista especializada y a elites, en la cual se enfatiza la definición de la situación del entrevistado, animándolo a estructurar el relato de la situación y a incorporar sus nociones de lo que considera relevante. 
incluyen las dehesas a pastos y también el erial y el matorral cuando sobre ellos se haya realizado algún aprovechamiento ganadero".

Son estos conceptos, especialmente la diferenciación entre prado cortado a siega y prado aprovechado a diente (pastoreo) los más recurrentes en la investigación puesto que el proceso a describir que conduce desde la pradera hasta el abandono del uso agrario pasa por ambos estadios.

\section{Resultado de la investigación: la cesión en precario en el origen de la subexplotación}

La indagación se estructura en función de los interrogantes planteados, con unos resultados distribuidos en tres bloques: grado de abandono de la actividad ganadera en el País Vasco; incidencia en un paisaje de pradera conformado entorno al aprovechamiento ganadero; e interés y posibilidad de distribución del usufructo agrario entre los que continúan. En el apartado relativo a la discusión de los resultados se abordarán los escenarios futuribles y las posibles medidas correctoras.

\subsection{La ganadería: una actividad marginal en el caserío vasco}

Estudios recientes, publicados a lo largo de la segunda década del nuevo milenio (Murua, 2012; Ruiz Urrestarazu \& Galdós, 2011; 2013a) analizan la cuestión del abandono de la actividad agraria en el País Vasco acudiendo a un estudio pormenorizado de las fuentes estadísticas. De los mismos obtenemos una serie de conclusiones que permiten analizar el grado de abandono de aquella actividad que condiciona el paisaje vasco atlántico, la ganadería:

- La intensidad del abandono agrario se acelera en la última década. En el caso concreto del País Vasco desde 1989 a 2009 desaparecen 10735 explotaciones de las que cumplen los requisitos del último censo. En cifras relativas esta disminución supone una pérdida del $40 \%$ de las explotaciones en veinte años. Y lo que es aún más significativo, las dos terceras partes de los abandonos se producen en el decenio más reciente.

- Si nos ceñimos a las explotaciones ganaderas, especialmente bovino, cabaña que mayor influencia tienen en la conformación y mantenimiento del paisaje rural, durante el período analizado el porcentaje de explotaciones que cesan su actividad es del 42,6 \%. Sin embargo, el número de cabezas de bovino no ha menguado en un porcentaje equiparable, sino que su caída ha sido menor. De cada cuatro cabezas que se registraban en 1999, solo se han mantenido tres en 2009.

- La tendencia que ya se había detectado y estudiado en décadas precedentes sobre el cambio de muchas explotaciones de una dedicación láctea a otra cárnica se ha incrementado de manera espectacular en el último intercensal. Pero el número de cabezas que no son vacas lecheras 
también ha disminuido. En definitiva, en 2009 había menos cabezas de ganado bovino que en 1999 en cualquiera de las orientaciones productivas.

- Si un número considerable de explotaciones lácteas han desaparecido pero el descenso en el número de cabezas no ha sido tan grande, la conclusión es obvia: las explotaciones que permanecen han adquirido una mayor intensidad ganadera.

La explotación de referencia en los valles vasco atlánticos es el caserío y, aunque los resultados censales se refieren en buena medida a sus características, no siempre reflejan correctamente la situación que atraviesa esta tipología de explotación. En el marco de esta investigación participamos en dos estudios locales que nos permite afinar la incidencia del proceso de abandono (Alberdi, 2018). En el primero, se analizan el registro de explotaciones de 285 caseríos del medio rural de San Sebastián (Zuazagasti, 2014) cuyos resultados nos aproximan a las características actuales de esta explotación, que resumimos de la manera siguiente:

- Reducida base territorial, con un tamaño medio por explotación de 6,11 Ha, y con una SAU media de 3,6 Ha.

- Porcentaje de caseríos con orientación ganadería aún es mayoritario, el 66,38\% de las censadas en el municipio, aunque ya no es exclusivo.

- Entre los usos predominan los prados, que representan algo más del $69 \%$ de la superficie total vinculada a las explotaciones, aprovechadas en porcentajes similares tanto a siega como a diente, seguido muy de lejos de la superficie destinada a las plantaciones y usos forestales $(18,8 \%)$.

- Las tierras se explotan en régimen de propiedad, el 55,83\%, mientras el resto es usado en arrendamiento u otros regímenes, preferentemente suelos cedidos a cambio de su limpieza.

- La estructura de las explotaciones agrarias del municipio está caracterizada por el predominio de la explotación de pequeña dimensión económica de las que un 94 \% tiene una dimensión inferior a 12 U.D.E. ${ }^{5}$

- Apenas el $6 \%$ de las unidades censadas presentan una dimensión económica significativa, de las que la mitad se dedica prioritariamente a la ganadería, distribuida a partes iguales entre vacuno, tanto de leche como de carne, y ovino.

Si el ejemplo de Donostia nos sitúa ante una tipología de explotación de tamaño reducido, con una dedicación marginal y con el prado como uso prioritario de la heredad, los estudios realizados en el municipio de Usurbil el año 1996 y su revisión el año 2015 nos aproximan a la evolución que esta tipología presenta. En ambos se entrevista en profundidad a la totalidad de los 143 caseríos que en 1996 presentaban actividad agraria y a las 116 explotaciones que mantenían actividad el

5 U.D.E.: Unidad Dimensión Económica: 12 UDE es el equivalente a 1200 euros de margen bruto estándar. 
año 2015. El último toma como referencia al primero y mantiene un guión similar. El objetivo que persigue es el de observar la evolución de la actividad agraria en los caseríos del municipio 20 años después. Resumimos las conclusiones que obtenemos del análisis comparativo de ambos trabajos (ver Tabla 1).

La primera de conclusión es la reducción del número y del grado de dedicación. Actualmente hay 116 operando en el sector primario cuando hace dos décadas eran 143. Un $20 \%$ de los caseríos han abandonado toda actividad en este periodo.

De ellas, solo 19 trabajan en el sector profesionalmente (algún miembro vive de la actividad), y el resto, es decir, 83,6\%, lo hace de manera parcial (parte de la producción destinada a la venta) o esporádicamente (autoconsumo). Las explotaciones que emplean a población a tiempo completo se reducen, por tanto, en un tercio en el periodo estudiado.

El elemento realmente llamativo de este periodo ha sido la reducción del grado de dedicación agraria del caserío. Del dominio de un caserío de dedicación parcial, que destinaba parte de su producción a la venta se ha pasado al predominio de una explotación que produce tan sólo para su autoconsumo (65,5\%). Ésta apenas mantiene una pequeña huerta y, en algunos casos, alguna unidad ganadera, ovino y equino normalmente, que le permite mantener parcial o totalmente el uso de la heredad mediante pastoreo. La cesión a terceros de parte de la heredad es práctica habitual en el municipio.

Tabla 1. Evolución de la dedicación agraria en Usurbil entre 1996 y 2015

\begin{tabular}{|c|c|c|c|c|}
\cline { 2 - 5 } \multicolumn{1}{c|}{} & CASERÍOS & EXCLUSIVA & PARCIAL & AUTOCONSUMO \\
\hline 1996 & 143 & $28(19,5 \%)$ & $78(54,5 \%)$ & $37(26 \%)$ \\
\hline 2015 & 116 & $19(16,4 \%)$ & $21(18,1 \%)$ & $76(65,5 \%)$ \\
\hline
\end{tabular}

Fuente: elaboración propia a partir de Altuna (1996), Uriarte (2015) y Alberdi (2018)

Tomando como referencia las de dedicación exclusiva y parcial, teniendo en cuenta que una explotación puede tener más de orientación productivo, observamos que si el descenso es generalizado son las explotaciones de vacuno de leche las que en mayor medida han desaparecido (ver Tabla 2).

Entre las que ejercen la actividad a tiempo completo son las hortícolas las mayoritarias, aunque entre todas estas la mitad admite que su intención es dejar a corto o medio plazo esta actividad, preferentemente, por falta de relevo en la explotación. Entre las explotaciones de dedicación parcial dominan las especializadas en ganado de carne (62\%) junto a aquellas que mantienen o combinan esta actividad con manzana de sidra (43\%). 
Tabla 2. Orientación productiva de las explotaciones de Usurbil con dedicación exclusiva y parcial. 1996 y 2015

\begin{tabular}{|c|c|c|c|c|c|c|c|}
\cline { 2 - 7 } \multicolumn{1}{c|}{} & LECHE & CARNE & CORDERO & CRÍA & OTRO & VERDURA & MANZANA \\
\hline 1996 & $7(26 \%)$ & $45(31 \%)$ & $24(17 \%)$ & $7(5 \%)$ & - & $31(22 \%)$ & $36(25 \%)$ \\
\hline 2015 & $2(1,7 \%)$ & $17(14,7 \%)$ & $4(3,4 \%)$ & $1(0,8 \%)$ & $4(3,4 \%)$ & $11(9,5 \%)$ & $16(13,8 \%)$ \\
\hline
\end{tabular}

Fuente: elaboración propia a partir de Altuna (1996), Uriarte (2015) y Alberdi (2018)

Los datos vienen a completar los obtenidos a través de la comparación de los diferentes censos agrarios y confirman que no existe tal concentración productiva sino una marginalización generalizada de la función ganadera del caserío, un proceso que aún parece no haber finalizado.

El cambio que se está dando en la actividad agrícola desde la década de los noventa es observado en numerosas investigaciones que desde distintos ámbitos cientificos se han ido realizando estas últimas décadas, al menos en el ejemplo vasco (Ruiz Urrestarazu \& Galdós, 2005). Una de las pioneras, realizada para el conjunto de España y tomando como unidad central de análisis la familia agraria (Etxezarreta et al., 1995), trata de definir los procesos de ajuste que inicia para adecuarse a este momento de cambio, llegando a diferenciar tres grandes formas de conducta: profesionalización, regresión y reproducción estable en aquellas con una clara vocación ganadera. ${ }^{6}$ Si las tendencias son equiparables y coincidentes, todo parece indicar que el abandono estaba más avanzado en el caso vasco, con un $80 \%$ en fase ya regresiva a inicios del milenio (Ainz, 2001) ${ }^{7}$. El ejemplo de Usurbil marca un paso más en la intensidad del abandono de la ganadería, con una única tendencia evidenciada, la regresiva. ${ }^{8}$

\subsection{Evolución de los usos: de la pradera al pasto, también en las tierras laborables}

Se ha de suponer que la drástica reducción de la cabaña ganadera acarreará cambios importantes en el paisaje rural vasco, en la medida en que buena parte de dicha cabaña se sustentaba en el aporte energético procedente del prado. La información estadística publicada denota más bien que

6 El mismo patrón será testado en el caso vasco por Mauleón (1998) y corroborado en posteriores trabajos que desde distintas perspectivas analizan la continuidad de las explotaciones agrarias (Ramos, 2009).

7 Dentro del proceso hacia la profesionalización, la línea tradicional es la única desarrollada y la actitud productivista la dominante. La regresiva incluye desde agricultores a tiempo principal, que por edad abandonan progresivamente la actividad, hasta familias en las que la agricultura presenta un carácter económico residual. La reproducción estable coincide con lo señalado, observándose dos tendencias principales, la correspondiente a las que ya realizaron un esfuerzo de modernización y la constituida por explotaciones que combinan actividades externas, sobre todo asalariadas, con las de la explotación. En Asturias, resaltando un ejemplo próximo al área de estudio, el $27,6 \%$ presenta una tendencia profesionalizada, el 61,1\% una reproducción estable y el 10,6\% una situación regresiva.

8 Otras informaciones, también centradas en ejemplos locales, vienen a confirmar que el ejemplo de Usurbil no es un caso aislado aunque tal vez sea la información más completa y distanciada respecto a la evolución del caserío mediante un ejemplo local (Madinabeitia, 2001; Murua, 2000; Osoro, 1997). 
las implicaciones de la reducción de la carga ganadera apenas afectan a la extensión de los prados. Sirvan como ejemplo las siguientes referencias:

- Según los datos de los últimos censos agrarios (1999-2009) se observa en el País Vasco un retroceso muy considerable, próximo a un tercio de su superficie, del pasto permanente. Este considerable descenso, sin embargo, no tiene por qué ser interpretado necesariamente como un cambio de ocupación del suelo, sino que en gran parte al menos se debería a una pérdida de función ganadera de esos espacios, que sin embargo conservan por ahora su vegetación herbácea, al haber disminuido el montante de los ganados (Ruiz Urrestarazu \& Galdós, 2013a).

- Otras fuentes estadísticas, como el Anuario de Estadística (última referencia año 2013), muestran como la superficie de herbazales permanece inalterada a lo largo de esos diez años. No habría habido cambios en el uso y daría fuerza a la interpretación funcional que se ha realizado de los resultados censales.

- La información suministrada por el Inventario Forestal del año 2005 y las imágenes del proyecto CORINE de los años 1987 y 2000 (Porcal et al., 2009) no muestran alteraciones de importancia en ámbitos ganaderos. Se comprueba un retroceso superficial de prados y praderas, de escasa envergadura, a favor de la expansión del matorral boscoso de transición, y de la urbanización, aunque también se registra un ligero aumento del espacio ocupado por los pastizales. La información recogida en CORINE relativa al inventario del año 2010 y publicada en 2012 tampoco muestra alteraciones relevantes en el caso de prados y pastizales.

- El último inventario forestal (2016) no presenta variaciones significativas respecto a la extensión de la pradera, al menos desde el inventario de 1986. Sirva como ejemplo que en Bizkaia ese año inventariaba como SAU 43000 Ha, mientras el año 2016 ya bajo la calificación de prados eran $39000 \mathrm{Ha}$ Es más, si hay alguna característica a resaltar de los últimos periodos intercensales (2005-16) es la estabilidad que presenta la superficie de este aprovechamiento. ${ }^{9}$

Una apreciación exclusiva de los datos estadísticos bien nos pudiera llevar a una interpretación incompleta del fenómeno que se está gestando, tal y como hemos observado en los resultados de abandono y marginalización de la ganadería. De hecho, otras investigaciones que analizan la evolución de los usos agrarios del País Vasco y que profundizan en las fuentes estadísticas e incluso en la entrevista apuntan cambios relevantes en los aprovechamientos ganaderos, ya visibles desde el inicio de la década de los noventa, cuando comienza a materializarse el paso de ganadería intensiva (vacuno de leche) a extensiva (vacuno de carne), y con ello el territorio agrario se vuelve a gobernar según el viejo sistema pastoril de carácter trashumante. Ello no genera

9 Desde el año 2005 y de manera ininterrumpida Hazi resume los resultados de los inventarios forestales relativos al País Vasco. En ellos se hace un estudio comparativo de la evolución que las distintas especies y usos presentan en este territorio (http://www.nasdap.net/inventarioforestal). 
cambios en el fondo de los valles, cuyos prados son segados asiduamente, pero sí en zonas intermedias y altas, que pasan ahora a ser aprovechadas mediante pastoreo (Ainz, 1994).

Investigaciones más recientes, centradas en la pérdida de espacios agrarios por artificialización y forestación, llegan a la conclusión de que en el País Vasco el retroceso de la SAU se debe a la pérdida del espacio dedicado a prados y labores intensivas, a favor de los pastizales, transformaciones acordes con la progresiva extensificación de muchas explotaciones ganaderas (Ruiz Urrestarazu \& Galdós, 2013b).

Con el objeto de completar y corroborar estas apreciaciones optamos por recurrir a ejemplos locales y al análisis parcelario para completar la información aportada (Alberdi, 2018). En este epígrafe vamos a analizar la situación observada en dos barrios rurales, dirigiendo nuestra atención hacia casos que a priori bien pudieran presentan un estado más avanzado en el proceso hacia la marginalización y el abandono. El primero, por mostrar un importante número de explotaciones menores de $1 \mathrm{Ha}$ y, el segundo, por un proceso de orientación ganadera tradicionalmente más extensiva (Ovino), según el censo agrario del año 2009.

Concertamos una serie de reuniones con los alcaldes de barrio, personas que le representan y que forman la comisión de la zona rural, que todavía pervive en estos ayuntamientos. Ellos nos informan tanto de la evolución que ha tenido la función agraria en cada una de las explotaciones de su barrio como de de los usos el suelo que tenían las parcelas de dichos caseríos, utilidad que podemos contrastar con la que se les aporta actualmente. Los aprovechamientos actuales han sido obtenidos a partir de la observación directa de estas superficies y los de 1990 a partir del análisis de la ortofoto completadas con las referencias de la población local.

En el barrio de Montaña (Hondarribia), el espacio agrícola utilizable está constituido básicamente por prados que, en la mayoría de los casos, mantienen su uso habitual (forraje o pastoreo). Sin embargo, encontramos por primera vez indicios evidentes de explotaciones cuya heredad muestra un alto grado de subexplotación e incluso de abandono.

Entre los cambios observados resalta el paso de la pradera al pastoreo al que se le aporta un único corte anual o pasan a ser aprovechadas directamente a diente. Los pastizales ubicados en zonas con menos posibilidades agrícolas son, en este período, mayormente descuidados. Se inicia en ellos un proceso de regeneración natural, combinándose con las gramíneas, aliagas, helechos y especies de porte leñosos. También algunos prados entran en desuso directamente aunque éstos son los menos. La superficie dominada por el matorral o el monte bajo apenas aumenta y si lo hace es a cuenta de algunas parcelas de pastizal que ya estaba semiabandonado en el período anterior o por algún pinar que tras su tala no ha sido repoblado. 
De la observación de la información y su contraste con los alcaldes de barrio, deducimos un proceso evolutivo más o menos genérico en las explotaciones del área en estudio. Partiendo de una base productiva totalmente mecanizable, presenta las siguientes fases:

- Hasta iniciarse la década de los noventa estos terrenos eran praderas de las que se obtenían anualmente entre tres y cinco cortes de hierba.

- Progresivamente, desde mediados de los noventa, el ganado, tanto vacuno como ovino, comienza a pastar en estos terrenos. El disfrute a diente se completa con un corte anual.

- En los primeros años del nuevo milenio se consuma el abandono de algunas parcelas y la infrautilización de la mayoría, bien con ovino bien con bovino y recientemente con equino. En todos ellos encontramos forraje sin cortar y aparecen las primeras matas de matorral.

La razón principal que lleva al desuso de la superficie mecanizable es la falta de mano de obra familiar o vecinal dispuesta a aportarle una utilidad adecuada. Si la cesión o arrendamiento ha funcionado hasta nuestros días, con la jubilación y pérdida de los pocos agricultores que se mantienen en activo, se ofertan terrenos que ahora ya no se aprovechan.

Los cambios acaecidos en los usos del suelo entre 1990 y 2016 en el barrio de Karrika, Oiartzun, muestran el proceso de extensificación generalizado al que hacemos referencia. Aquí también la alteración principal se produce como consecuencia del paso de prado y pradera para forraje a pastoreo a siega (una corta) o a diente. En este caso, las zonas en desuso son escasas y se reducen a pequeñas parcelas marginales. Las áreas de cultivo y frutales mantienen su anterior superficie e incluso, a pesar de haber sido abandonada alguna pequeña parcela, el helechal conserva su uso. Se constata también el descuido de algunos terrenos ocupados por pinares, que ahora pasan a constituir básicamente monte bajo y tampoco se observan nuevas superficies repobladas con pino.

Con una situación algo distinta a la de Montaña, el barrio de Karrika muestra los efectos de la extensificación ganadera que se ha producido en estas décadas. La dinámica que descubren los usos del suelo agrícola utilizable indica que el proceso de abandono todavía no está tan avanzado; algunos caseríos aportan un corte al terreno mecanizable y después aprovechan la heredad a diente; otros han cedido el uso a terceros; los menos utilizan el terreno para pastoreo y la siega la realiza un tercero a cambio de una parte proporcional del forraje obtenido; y en algunos casos se consume directamente, sin ninguna corta. Es previsible que la evolución, sin embargo, sea similar, si bien la existencia de explotaciones al frente de las cuales se sitúa población joven, en este caso especializadas en ovino, parece ser garantía de mantenimiento de gran parte de los usos actuales (ver Figura 1). 
Figura 1. Aprovechamiento actual del suelo destinado

a pradera y prado forrajero en Oiartzun (Karrika) el año 1991

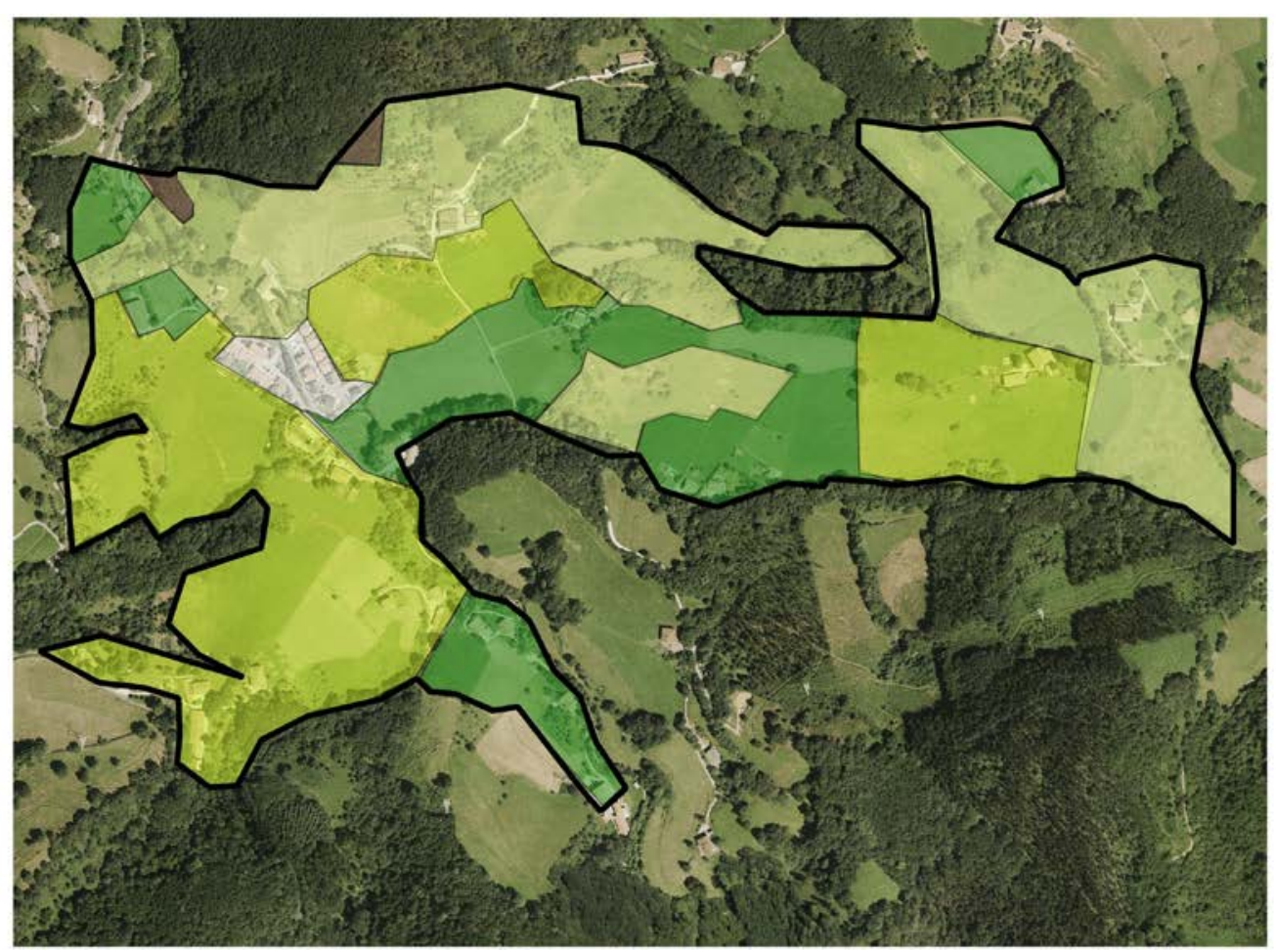

Pasto a diente

Pasto con siega

Prado abandonado

Prado forrajero

Crecimiento urbano

$0 \quad 1000020000 \mathrm{~m}$

Fuente: elaboración propia, ortofotos (1991-2017) y entrevistas

La extensificación y abandono de áreas aprovechadas para usos ganaderos abre al aprovechamiento forestal la oportunidad de disfrutar de nuevas y mejores parcelas. Sin embargo, en los ejemplos descritos observamos más bien el proceso contrario, con algunas parcelas que, tras la tala, no son repobladas, Algunos investigadores ya apuntan al agotamiento del modelo forestal vasco desde inicios del nuevo milenio. Para éstos, la reforestación de suelos abandonados con fines comerciales no constituye una alternativa con visos razonables de prosperar. Es más, consideran más probable que se agudice el abandono de superficies forestales a favor de la reforestación espontanea a que ocupe suelos agrarios dedicados a otros usos (Murua et al., 2012). Los datos aportados por el último inventario forestal (2016) no hacen sino corroborar estas afirmaciones.

Ni siquiera el abandono de pastos y prados, en un momento de crisis de las actividades ganaderas, beneficia al desarrollo de las actividades forestales. Si en otra coyuntura los usos silvícolas sustituyeron a los ganaderos, coincidiendo con momentos de falta de mano de obra en el caserío, actualmente, ante un problema similar, la superficie repoblada, lejos de aumentar, disminuye, a favor del denominado bosque atlántico, surgido espontáneamente y caracterizado por especies de bajo porte. 


\subsection{Entre la subexplotación y la cesión del disfrute de la heredad}

El equilibrio actual de los usos agrarios se apoya, salvo excepciones, en un aprovechamiento muy extensivo y puntual de los prados para pastoreo, y en un sistema de contratos en precario por medio de los cuales aquellas explotaciones que abandonan toda actividad ganadera ceden a un tercero el usufructo de parte o la totalidad de la heredad. ${ }^{10}$

Es difícil precisar qué porcentaje real del suelo agrario es utilizado por arrendamientos o contratos en precario, pero según algunas estimaciones oficiales (Encuesta sobre la Estructura de las Explotaciones Agrarias del INE, 2017), supone el $51 \%$ de la superficie utilizada por las explotaciones en el País Vasco. El censo agrario del año 2009 estima unas cifras sensiblemente inferiores, próximas al $31 \%$ de la SAU, mientras los resultados que aportan estudios más localizados (Donostia, Usurbil), oscilan entre el $29 \%$ y el $46 \%$ del total de la SAU. De un modo u otro son resultados significativos para entender el equilibrio actual de los usos del suelo.

Respecto a los datos relativos a las condiciones que presentan este tipo de suelos para la actividad agroganadera (Alberdi, 2002), todo indica que son sensiblemente mejores que los de propiedad, son totalmente cultivables el 59,8\%, mientras los que no permiten ningún tipo de mecanización no suponen más que el 3,6\%. La calidad de la parcela está relacionada con sus posibilidades de roturación y, según ésta, el 65,4\% es apta para ser labrada, y para pastoreo permite su uso el 28,1\%. El espacio dedicado a prado o pasto es casi su única utilización reseñable, destinando a hierba para forraje el 86,6\% de su superficie. La cesión o arrendamiento de este tipo de parcelas se realiza casi exclusivamente para la obtención de hierba y con una intención bien clara por parte de su propietario, mantener el uso agrícola del suelo.

El abandono de la actividad de unos repercute en el incremento del suelo utilizado por otros y en el mantenimiento de los usos forrajeros. El resultado esperado sería el de una concentración de la capacidad productiva en un reducido número de explotaciones. Pero, siendo el abandono tan intenso y tan pocos los que optan por su continuidad, ¿̇están estos últimos interesados en continuar con el aprovechamiento de toda la superficie forrajera?

Las necesidades de suelo que plantea el ganadero que continuará, sus posibilidades de mano de obra y el modelo de alimentación que elija van a repercutir en un mayor o menor abandono. Se convierten en caseríos estratégicos para el mantenimiento del suelo agrícola útil y, aun así, es más que probable que su demanda sea insuficiente para conservar el uso de la superficie actual.

10 Los propios ganaderos utilizan la definición de Garbitzealde o a cambio de su limpieza para referirse a este tipo de arrendamientos en precario, no declarados, por los que habitualmente no se abona cantidad alguna salvo la exigencia del mantenimiento en uso de la heredad. En estas zonas, las tierras no utilizadas en propiedad son arrendadas o cedidas, normalmente bajo la fórmula de contratos en precario, que potencian el desarrollo de unos aprovechamientos extensivos. Así, la extensificación se puede generalizar, incluso en las parcelas que mejores condiciones agrológicas presentan (Alberdi, 2002). 
Con el objeto de analizar las estrategias territoriales que presentan los ganaderos con una continuidad manifiesta hemos procedido a realizar 11 entrevistas entre Enero y Febrero de 2018, dirigidas a los titulares de los distintos modelos de explotaciones que observábamos, centradas en cuestiones diferentes, cuestionándoles sobre el uso actual de la SAU, necesidad de suelo a medio plazo, cambios que observan en los usos del suelo del espacio agrícola.... Los grupos diferenciados son los siguientes: vacuno de leche fundamentado en alimentación exterior, vacuno de leche con aporte alimenticio propio, bovino de carne y explotación de ovino. Completamos los resultados con una entrevista realizada a un técnico de Oficina Comarcal Agraria, responsable de la tramitación de los derechos de superficie destinados a cubrir el Pago Único, y a un responsable de la campaña de saneamiento animal, y conocedor de la realidad que atraviesan las explotaciones agrarias.

De la entrevista con los ganaderos, teniendo en cuenta las particularidades y manejos difieren de un modelo a otro, se observan una serie de resultados similares respecto a las cuestiones planteadas. Respecto al uso actual del suelo agrario utilizable obtenemos las siguientes conclusiones:

- La SAU media de las explotaciones entrevistadas en propiedad es de 5,4 Ha, correspondiéndose con la habitual del caserío vasco (Ainz, 2001).

- La SAU media utilizada es de 29,4 Ha En todos los casos los suelos cedidos o arrendados, siempre mediante acuerdos en precario, al menos cuadruplican al de propiedad y en un caso incluso multiplican por quince dicha superficie.

- Más de dos tercios del suelo utilizado es mecanizable, preferentemente prados, a las que aportan alrededor de tres cortes de hierba anuales. Tan solo las explotaciones de ovino constituyen una excepción pero sólo relativamente, pues aportan habitualmente dos cortes al espacio utilizado.

- Las no mecanizables, normalmente de su propiedad, se ubican próximas a la explotación. El resto de aprovechamientos lo constituyen preferentemente prados, mayormente cedidos y arrendados, combinados con alguna parcela destinada a cultivos forrajeros (maíz).

Es evidente que estas explotaciones han acumulado buena parte del suelo utilizable de las que han optado por abandonar o marginalizar la cabaña. Pero no lo han hecho con toda su superficie sino que se han centrado preferentemente en el suelo mecanizable.

Cara a un planteamiento de futuro la superficie que estaría interesado en incorporar es reducida y preferentemente laborable, que pretenden destinar a la obtención de forraje. Muestran su deseo de utilizar nuevas parcelas pero reconocen que éste se topa con dos obstáculos:

- Falta de mano de obra suficiente en la explotación para disfrutar más suelo del que actualmente utilizan. 
- Oferta reducida y de baja calidad entre las tierras que les proponen. Son ya parcelas alejadas, de reducido tamaño, semiinvadidas por el matorral, entre árboles, con cierres en malas condiciones...., lo que les lleva a desestimarlas.

La superficie no mecanizable sólo es demanda por las ganaderías de ovino y, en menor medida, por las de vacuno de carne, siempre y cuando se sitúe próxima a la explotación. Este hecho es evidente en las ganaderías de ovino que aprovechan durante el día el terreno que mejores condiciones energéticas presenta para la cabaña y duerme durante la noche en aquel de mayor desnivel (Guzmán, 2017).

Respecto a la situación que observan en los usos del suelo agrario de sus proximidades, opinan que el terreno laborable mantendrá su uso. El de más desnivel, sin embargo, y especialmente en los casos en que esté lejos de las explotaciones, perderá su uso agrícola y se abandonará.

La entrevista al técnico de la Oficina Comarcal Agraria y al Técnico de la Campaña de Saneamiento Animal, ambos de la Diputación Foral de Gipuzkoa, la centramos en torno a las posibilidades que el nuevo escenario de ayudas por parte de la PAC abre a una nueva redistribución del disfrute de los suelos agrarios. En términos generales no esperan que ello origine cambios significativos y para ello apuntan los siguientes argumentos:

- La explotaciones con subvenciones inferiores a $3000 €$ perdían sus derechos el año 2017. Muchas pequeñas explotaciones, en clara situación de marginalidad, se situaban en este grupo. La aportación económica no estimula a estas antiguas ganaderías.

- Estos derechos podían ser transferidos a un tercero y, sin embargo, esto no ha ocurrido y la mayoría de las explotaciones han optado por perderlos. ${ }^{11}$ Esta realidad se explica por el propio sistema de arrendamiento utilizado en el caserío vasco según el cual mayoritariamente son los propietarios los que declaran el disfrute del suelo aunque sean otros los que aprovechen la tierra. El propietario está dispuesto a ceder el usufructo de su heredad pero siempre de manera oculta, y contar así en todo momento con la disponibilidad de la tierra.

- Una nueva reorganización del reparto de derechos sobre el usufructo del suelo, similar a la que ahora propone la PAC, no traerá cambios excesivos en el actual modo de funcionamiento. Son otros razonamientos los que imperan a la hora de decidir ceder el suelo, o de optar por mantener de manera muy extensiva, (culturales, especulativos, sentimentales, paisajísticos...).

11 La nueva propuesta de la PAC de la Comisión Europea trata de poner fin al actual régimen de pago único y que se establezca un nuevo "pago básico" por hectárea que deberá definirse en los próximos meses. La definición de hectárea admisible y la cantidad de ayuda uniforme por hectárea, suscitan gran preocupación para el sector español de vacuno. Son varias las investigaciones que analizan este tema, tanto desde una óptica sectorial como desde una visión regional. Recomendamos a este respecto consultar las investigaciones de Blanco et al. (2011) y Hernández (2012), la primera desde una óptica regional y la segunda desde una visión sectorial. 
Asimismo, confirman algunas apreciaciones realizadas por los ganaderos profesionales, entre ellas la dificultad de que éste utilice más suelo que el actual dado que carece de mano de obra suficiente. De hacerlo, sería de un modo muy extensivo, reduciendo el número de cortas y obteniendo unos resultados energéticos muy pobres, situación que no consideran ni probable ni recomendable.

\section{Discusión de los resultados: actuar desde la escala global a la local}

Los resultados obtenidos dejan entrever que la gestión del espacio utilizable del caserío vasco se apoya preferentemente en una tipología de explotación que carece de cualquier objetivo económico, que aprovecha la producción que obtiene para autoconsumo y que conserva una reducida cabaña ganadera para mantener en uso la heredad.

La explotación descrita frena el escenario tradicional al que el abandono de la ganadería lleva en regiones de montaña, la regeneración natural de la vegetación. Aun así, en las parcelas más alejadas, en las de menos capacidad agrológica y en las zonas sin explotaciones ganaderas de envergadura no se observan muchas posibilidades de continuidad de los usos actuales y en estas, al igual que en otras regiones de montaña, la regeneración natural de la vegetación es la opción más previsible. Esta alternativa, sin embargo, se topa en esta región con varias apreciaciones que, al menos por el momento, limitan su expansión y que consiguen mantener en uso la campiña.

1. Observamos entre los agricultores y ganaderos una clara conciencia de aprovechamiento productivo del suelo. Todavía hoy en día no se concibe en el mundo agrario un terreno sin utilidad. A pesar de que el abandono es una situación presente, también lo es la necesidad de mantener la explotación limpia. ${ }^{12}$ En algunos casos, consultados por esta cuestión, aducían la necesidad de limpiar y cuidar el espacio agrícola, hobby hacia una función, la ganadera, siempre presente en casa, o la sensación de tristeza que provocaba ver el patrimonio familiar abandonado. ${ }^{13}$ Estos razonamientos descubren una gran carga cultural.

2. Las ayudas de la PAC, en el caso del caserío vasco el Pago Único y las Indemnizaciones Compensatorias de Montaña (ICM) preferentemente, contribuyen a frenar el proceso de

12 Observamos que las generaciones más jóvenes no han conocido ni se les ha trasmitido los valores de una sociedad protoindustrial. La pérdida de esa población supone una importante pérdida de recursos con unas claras implicaciones espaciales. En este sentido, Gomez Orea apunta cómo "los franceses han defendido una frase significativa -le monde rural gardien de la nature-, que pone de relieve la importancia de los hombres del agro en el mantenimiento de los equilibrios y paisajes; no sólo de aquellos en los que el hombre interviene, producto de una relación juiciosa y pausada, sino de otros estrictamente naturales" (1992, p. 70).

$13 \mathrm{El}$ mantener en propiedad unos terrenos agrícolas a los que no se les aporta ningún uso es una situación habitual. Sin embargo, la conciencia de preservar el uso agrícola, no siempre está presente. En Galicia, según López Iglesias, se observa "la preferencia de muchos propietarios de tierras libres por conservar éstas en su poder y dedicarlas a la producción forestal, antes que venderlas o arrendarlas a un agricultor. Fenómeno este que con frecuencia parece responder no tanto a la rentabilidad corriente que ofrece esa producción, sino al interés en conservar las superficies como activo o elemento del patrimonio" (1996, p. 502). 
abandono en la medida en que la exigencia principal para recibir el pago es un compromiso respecto al mantenimiento del uso agrario y contribuyen a complementar la economía del agricultor. Aun así, no son capaces de evitar por si solos el abandono de muchas parcelas de pequeños beneficiarios para los que esas ayudas no son interesantes.

3. Otra serie de investigaciones, normalmente ligadas a zonas agrícolas en las que la presión urbana es intensa, apuntan intereses especulativos por parte de los propietarios de los terrenos, que ven cómo el mantenimiento del uso agrícola en este tipo de espacios genera un efecto alcista sobre los precios del suelo. ${ }^{14}$ Una de las explicaciones que se aportaba en las entrevistas para no reforestar con coníferas era, precisamente, la pérdida de valor del suelo que presentaba la parcela.

Similares estrategias se reproducen en antiguas explotaciones que han abandonado la actividad y en las que el caserío ha dejado de ejercer la función agraria para convertirse en vivienda privilegiada en un entorno rural. El interés de sus propietarios es que este entorno se mantenga, lo que no sucedería si se acometiese una repoblación que acabase "comiéndose" a la vivienda (Ruiz Urrestarazu \& Galdós, 2013a), o si se perdiera el paisaje de campiña. Estos propietarios cederán el uso de sus parcelas para aprovechamientos ganaderos.

Dichos aspectos potencian el mantenimiento de los usos agrícolas, aun siendo éstos muy puntuales, y la continuidad de modalidades de cesión o arrendamiento a partir de contratos generalmente orales y, probablemente, lo continuarán haciendo.

Junto al modelo descrito pervive aún un caserío que hace de la ganadería un oficio, sea con dedicación exclusiva o parcial, que gestiona sus tierras junto a las de otras explotaciones que han ido abandonando la actividad. Este caserío acapara buena parte de los suelos, tanto del grupo que marginaliza como de aquel que ha optado por un abandono completo, gracias a fórmulas de arrendamientos precarios. Este grupo, sin embargo, es muy minoritario y continuará siéndolo aún más los próximos años.

Hemos observado que en las condiciones actuales aquellas explotaciones que ejercen esta actividad con criterios económicos no parecen interesadas en incrementar visiblemente el suelo que utilizan. Actualmente ya acaparan suficientes parcelas, carecen de tiempo y mano de obra para manejar muchas más y, de mostrar interés, sólo lo harán por aquellas que pueden ser objeto de uso con maquinaria agrícola.

14 Prost, en referencia a la agricultura en los espacios periurbanos, llega a esta conclusión, señalando que si muchos terrenos mantienen su uso agrícola es más por especulación que por su propio valor económico (1994). Distintas investigaciones analizan distintos ejemplos de zonas agrícolas periurbanas observando en todas ellas el efecto alcista que provoca en los precios del suelo este tipo de agricultura, a menudo ni siquiera realizada por los propietarios de los terrenos. 
Como consecuencia, el amplio espectro de parcelas agrarias no mecanizables, con pendientes superiores al $20 \%$, y que continúan manteniendo un uso ganadero, están actualmente en claro riesgo de matorralización bien porque el uso que se hace de ellas es tan extensivo que es incapaz de hacer frente a la regeneración natural de su cobertura vegetal o bien, sencillamente, porque carecen de interés agrológico para otro agricultor. ${ }^{15}$ Su extensión es sensiblemente superior a las parcelas mecanizables y, previsiblemente, un cambio en su vocación afectaría al equilibrio actual de usos del paisaje de campiña vasco (ver Figura 2).

\section{Figura 2. Prados en pendientes superiores al $20 \%$ : desarrollo de un ejemplo (Andoain)}

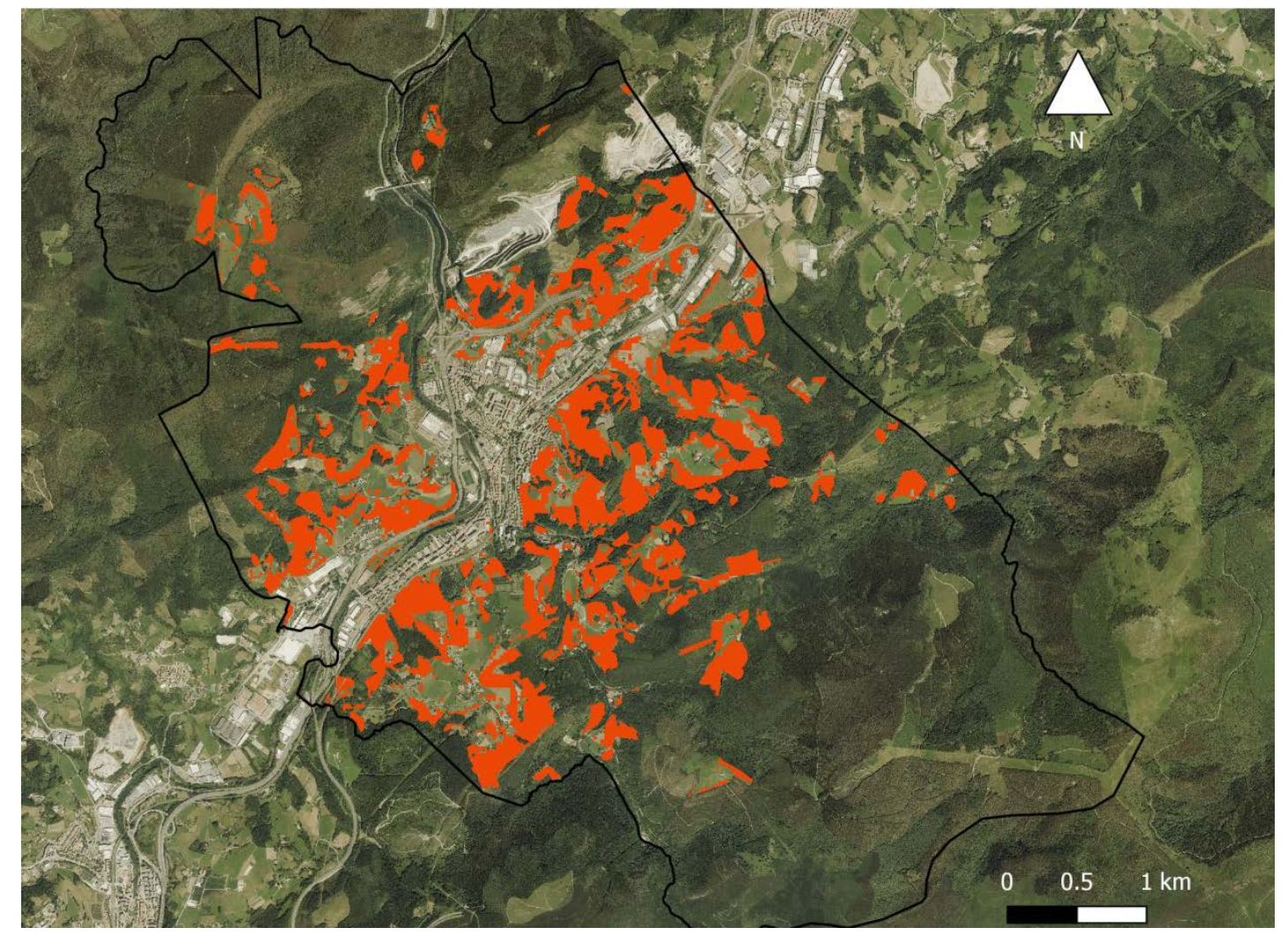

Fuente: Inventario Forestal (2016) y Mapa de Pendientes del País Vasco (2016)

Asimismo, aprovechamientos alternativos al abandono del suelo utilizable no parece que vayan a tener apenas trascendencia. Las repoblaciones de coníferas, una vez taladas, no son siempre reforestadas, regenerándose un arbolado de forma espontánea, caracterizado por su bajo porte y multitud de pies. Son muchos los aspectos que nos inducen a pensar que el desarrollo de la cubierta vegetal natural y en último caso del bosque surgido espontáneamente, será el destino de

15 Son varias las investigaciones que apuntan que en los campos abandonados como prados, el forraje de elevada calidad experimenta un descenso durante los primeros años de abandono, debido a la disminución inicial y posterior desaparición de las especies características de prados. La invasión de leñosos se inicia casi siempre rápidamente, y así la aliaga, la más representativa, penetra desde la periferia al centro mediante vainas explosivas que distribuyen las semillas a 2-4 m. de distancia (Cingolani et al., 2005). 
gran parte de los suelos agrícolas que van a perder su uso actual. Así está ocurriendo en otras zonas en las que el proceso está más avanzado y en esta dirección apuntan las tendencias que tanto en el terreno forestal como en el agroganadero hemos observado.

La inminencia del abandono de usos, representada actualmente en una reconversión casi generalizada de las tierras de labor y prados en pastos, está llevando a las instituciones y entidades que operan en el agro, dirigidos desde la PAC preferentemente, a plantearse distintas iniciativas que puedan paliar los efectos de la falta de mano de obra en su medio agrícola. En el marco de la investigación discutimos con los entrevistados sobre medidas que pueden contribuir a mantener el uso de la pradera. Las posibles soluciones se topan con la dificultad de superar la falta de mano de obra y el sistema de arrendamiento en precario que se desarrolla actualmente.

Las iniciativas propuestas pasan por potenciar las medidas de corte sectorial fomentadas desde instituciones públicas que, entre otros objetivos, pretenden ser un freno al abandono de determinados terrenos. El hecho de que la Comunidad Europea a partir del año 2000 ya decidiera que las subvenciones compensatorias se aporten en función de la superficie agraria utilizada por cada explotación ha sido un aliciente para mantener el actual espacio agrícola utilizable ${ }^{16}$ para muchas explotaciones. El anuncio realizado en la nueva PAC de modificar las ayudas del pago único y de centrarlas en SAU de los agricultores en activo abre una nueva posibilidad para incrementar las subvenciones, y contribuir a la continuidad de las explotaciones y a su reorientación cada vez más extensiva.

Sin embargo, estas medidas se consideran insuficientes. Los entrevistados proponen articular también acciones a nivel regional y, en un área de montaña sometida a una fuerte presión urbana, a promover políticas que ayuden a movilizar el disfrute de la SAU. El País Vasco cuenta con una figura para tal menester, los centros de intermediación agrarios y la movilización de suelo privado por infrautilización. ${ }^{17}$ Con este objetivo, la ley establece mecanismos para la conservación y actuación sobre espacios infrautilizados, hasta el punto que prevé procedimientos sancionadores. La clave y el secreto del régimen sancionador de la ley es que las fincas que estén en el centro de

16 "La concesión de las ayudas al vacuno establecidas en los artículos 6 a 9 de la presente sección estará supeditada a que la carga ganadera de la explotación del solicitante no exceda de dos unidades de ganado (U.G.) por hectárea; dedicada a la alimentación de los animales en ella mantenidas, de acuerdo con la declaración de superficie forrajera realizada por el solicitante" (B.O.E., n 307, 24/12/1997). "La totalidad del pago único que percibían los productores en el anterior ciclo de la PAC pasa ahora a integrarse en el pago básico. El pago básico es concebido como una ayuda por superficie, ya que la cantidad total del pago básico se divide entre el número de hectáreas de la explotación para dar lugar a los derechos de pago básico, que serán de una cantidad de dinero por hectárea. Para determinar el número de hectáreas de la explotación se analizarán las declaraciones del 2013 y del 2015 y se escogerá la cifra menor" (Brocos, 2015).

17 El Gobierno Vasco publica el 8 de octubre del 2012 el decreto Ley 193/2012 sobre promoción del uso y conservación del suelo agrario en el que regula el régimen sancionador por infrautilización del suelo agrario y en el que se habilita a las Diputaciones Forales a su desarrollo y aplicación. 
intermediación no sean multadas. Ello conlleva la cesión temporal de uso, por un plazo no inferior a diez años ni superior a treinta, a los fondos de suelo agrario de la parcela o parcelas implicadas.

El decreto de infrautilización, a pesar de estar aprobado, no se ha desarrollado (Llorente, 2014). Se parte de la convicción de que su materialización tal vez no aporte más suelo a la entidad de gestión, no al menos de buenas condiciones agrológicas, pero si se cree que puede ser una herramienta adecuada para movilizar los arrendamientos entre particulares. El propietario buscará ganaderos que quieran utilizar su heredad antes de verse sometido a un expediente sancionador $y$, aunque no acuda al centro de intermediación público, al menos se preocupará de que su heredad no pierda su uso.

La iniciativa local también puede jugar un papel destacado, especialmente para suplir la falta de mano de obra. De hecho se van desarrollando diversas iniciativas de esta índole. Impulsadas por una gestión local (Asociaciones de Desarrollo Rural) contribuyen a facilitar la correcta gestión de la heredad de la explotación y el aprovechamiento de sus recursos forrajeros aportando servicios de maquinaria y mano de obra a precios asequibles para el ganadero. Se trata en todos los casos de actuaciones centradas en la dotación de servicios de maquinaria exteriores, y que están contribuyendo a que el suelo mecanizable mantenga su uso forrajero. El alimento obtenido permite conservar una reducida cantidad de ganado que recibe como sustento exclusivo el heno ensilado, además de la hierba cortada a diente. ${ }^{18}$ Se propone reforzar y extender este tipo de iniciativas, ofertando los servicios de ensilado en unas condiciones aún más ventajosas. Con ello, se abarataría el precio del forraje, se impulsaría el consumo del alimento obtenido en la propia explotación o en la proximidad y se consolidarían toda una serie de servicios que contribuyen a mantener el uso del prado y el paisaje de campiña.

Junto a estas medidas se considera necesario impulsar el apoyo a la forestación de tierras agrarias no mecanizables que vayan perdiendo su uso. No es una medida popular entre un propietario que observa dicha forestación como una pérdida del valor, económico y cultural, de su heredad pero si sería una acción a promover y apoyar socialmente. Ello conlleva superar el actual sistema de explotación forestal intensivo y buscar nuevas formas de gestión de los ecosistemas forestales locales que, involucrando a diferentes actores sociales, permita mantener la multifuncionalidad de los ecosistemas y además, reconfigurar las relaciones entre el ámbito rural y el urbano. Los entrevistados apuntan que si se requiere del apoyo social es esencial hacer visibles las

18 En contra de lo señalado en otras investigaciones que resaltan la importancia del consumo de piensos en el ganado que pasta a diente, observamos cómo la alimentación, una década después, se hace exclusivamente a base de hierba ensilada en invierno y hierba cortada a diente entre primavera y otoño en muchas explotaciones, principalmente en aquellas que poseen una cabaña muy reducida, acorde a la capacidad energética que puede aportar su explotación. Se puede consultar más información sobre esta modalidad de actuación en Alberdi (2018). 
interrelaciones existentes entre la conservación de la naturaleza y el bienestar humano, potenciando con todo ello procesos de cooperación entre agricultores, instituciones y la sociedad en general.

La puesta en marcha de las medidas señaladas no requiere de recursos organizativos ni económicos excepcionales pero sí de una política de actuación inusual en el medio rural, ${ }^{19}$ como es la aplicación de un régimen impositivo a aquellos propietarios que no aprovechen las posibilidades agrológicas de sus tierras. Otro tanto ocurre con la política forestal propuesta, que supone un cambio evidente respecto a la promoción de un aprovechamiento intensivo del bosque impulsado desde las entidades sectoriales durante décadas.

En ambos casos se requiere un cambio de dirección progresivo, nunca radical ni traumático. Los resultados esperados difícilmente corregirán la decisión que tome un propietario que labora en la ciudad y sobre un suelo cuyo valor económico es aportado por sus posibilidades urbanas. Los logros, aun siendo previsiblemente interesantes, tan sólo suavizarán la pérdida progresiva del paisaje mixto de campiña atlántica vasca. La falta de mano de obra interesada en continuar con la actitud agrícola o ganadera dificulta la asunción de cualquier medida que pretenda revitalizar o impulsar un nuevo modelo agrario (Salvatori, 2011), pero la posibilidad de paliar los efectos esperados han de venir de la mano de políticas sectoriales transversales centradas en promover y facilitar el uso del suelo (Huber et al., 2013)

\section{Amortiguar los efectos paisajísticos del abandono ganadero, objetivo a abordar por las instituciones locales: a modo de conclusión}

El área comprendida por el caserío vasco, más que responder a un binomio intensificaciónabandono o sobreexplotación-infrautilización propio de zonas de montaña, responde a una extensificación generalizada de los usos, con un mantenimiento de la superficie agrícola utilizada. Es un hecho que muchos de los ganaderos que se mantienen hacen un uso más extensivo del territorio, aún a costa de que una parte de los espacios dedicados a la alimentación del ganado permanezcan infrautilizados (Ruiz Urrestarazu \& Galdós, 2013a).

Razonamientos culturales y económicos potencian esta situación, a los que se les ha de unir la política de la Comunidad Europea de conservación de la superficie utilizable, destinando buena parte de sus subvenciones a tal fin. Aun así, la hipótesis de partida, que plantea que el abandono de la actividad ganadera genera la pérdida de suelo agrario, no se está cumpliendo y el prado mantiene, al menos tras dos décadas de reducción continuada de la cabaña ganadera, su extensión.

19 Aunque no en el medio urbano, donde se ha hecho ya habitual abonar mayores impuestos por viviendas desocupadas o segundas residencias (García \& Rafael, 2007; Comelles, 2016). 
Pero su aprovechamiento se ha extensificado, incluso subexplotando hasta las zonas arables y muchas parcelas muestran síntomas evidentes de matorrizalización, lo que hace suponer que a medio plazo las parcelas más alejadas de la explotación y que peores condiciones agrológicas presentan, se van a ver, total o parcialmente, abocadas al abandono. El abandono de activos es generalizado y no hay un proceso de concentración de cabaña y parcelas agrarias. La explotación que continúa no demanda más suelo y sólo muestra interés por aquel susceptible de ser aprovechado con maquinaria agrícola.

Entre las consecuencias citadas habitualmente por la pérdida de espacios productivos (económica, social y ecológica), en el caso vasco es especialmente relevante la pérdida de calidad del paisaje. Las Asociaciones de Desarrollo Rural del País Vasco apoyan el progreso de su medio rural en iniciativas que revaloricen los productos agrarios y en la conjunción que realizan entre el medio rural y su paisaje. Para los responsables de la promoción rural, desarrollo, agricultura y mantenimiento del paisaje han de ser variables conexas y a partir de ellas el medio rural ha de buscar la aceptación del conjunto de la sociedad. ${ }^{20}$

Las medidas ante este proceso de infrautilización pasan por continuar potenciando las primas por hectárea utilizada mediante ayudas directas, bien sea recurriendo al pago único o bien por medio de las ICM. Centrarlas en los agricultores en activo, tal y como anuncia la nueva PAC, contribuirá a mejorar la maltrecha economía de las explotaciones ganaderas y a asentar un modelo de explotación más sustentado en la obtención de forraje propio, pero ha de estar completada con herramientas que dinamicen la movilidad del suelo, como pueden ser una intervención real que la potencie. En el marco de la investigación proponemos tres medidas de corte regional y local, todas necesarias de activación y promoción.

1. En primer lugar, activar los mecanismos legales existentes para la conservación y actuación sobre espacios infrautilizados (Decreto Ley 193/2012 sobre promoción del uso y conservación del suelo agrario) Si este decreto se pusiera en marcha obligaría al propietario a buscar ganaderos que quieran utilizar su heredad y, acuda o no al centro de intermediación público, se vería abocado a movilizar el uso de sus tierras.

2. Ofertar servicios de maquinaria agrícola (ensilado, sega, abonado...) organizados y promovidos por instituciones públicas. La medida ha estar dirigida a todos aquellos que la requieran, independientemente de la cabaña ganadera que posean. El equilibrio actual del uso del suelo

20 Dos trabajos dirigidos a testar la opinión de la ciudadanía respecto a su medio rural y a la producción agraria fueron realizados paralelamente en el País Vasco, uno impulsado desde IKT y el otro promovido desde las Asociaciones de Desarrollo Rural del País Vasco, recogidos por Arrieta (2009). La iconografía que el ciudadano describe es incompleta. Como señala Arrieta (2009), el medio rural permanece en la mente de algunos ciudadanos como una postal inerte, sin movimiento, desconociéndose la labor del agricultor. Muestra de ello es la escasa correlación que establecen entre la agricultura y el entorno natural cuando no se considera al agricultor como el responsable de la buena salud que presentan los entornos naturales. 
también recae en un propietario que mantiene una reducidísima cabaña ganadera, exclusivamente por razonamientos culturales e incluso sentimentales, dirigida a mantener en uso su heredad, patrimonio histórico de su familia.

3. Una última medida propuesta está dirigida a facilitar que el bosque recupere aquellos espacios que tanto las explotaciones intensivas como el prado y pastizal van abandonando, apoyando al propietario que opte por reforestar estas parcelas siguiendo un modelo de aprovechamiento del monte más consensuado con el sentir social y las demandas ambientales. Ello originaria una reorientación del actual sistema productivista centrado en el pino insigne hacia un modelo sustentado en el bosque autóctono y justificaría un mayor apoyo público.

Aun así, si la puesta en marcha de estas medidas puede atenuar la pérdida de buena parte del paisaje mixto de campiña atlántica no evitaran que la regeneración natural de la cubierta vegetal y, con ello, la pérdida de diversidad paisajística, continúe avanzando. Por el contrario, si las medidas iniciadas excluyen las actuaciones locales o regionales la matorralización del paisaje se extenderá y ocupará buena parte del espacio de la campiña de estos valles.

Agradecimientos: Esta investigación es fruto de en un proyecto de colaboración entre el Departamento de Geografía de la Universidad del País Vasco y las Asociaciones de Desarrollo Rural del País Vasco (ADR), dirigido por el redactor de este trabajo, con el código OTRI 2006.003. Gracias a dicha colaboración el autor ha podido participar en proyectos promovidos por estos entes y centrados en dinámicas locales, algunos de cuyos resultados son utilizados tanto en esta publicación, dirigida a analizar el equilibrio del paisaje atlántico vasco, y en una segunda, en la que se profundiza en una de las medidas que puede contribuir a su conservación (Alberdi, 2018).

Declaración responsable: El autor declara que no existe ningún conflicto de interés con relación a la publicación de este artículo. 


\section{Bibliografia}

Ainz Ibarrondo, M. J. (1994). Caserío en los valles atlánticos del macizo de Gorbea. Transformaciones recientes. Lurralde, 17, 281-294.

Ainz Ibarrondo, M. J. (2001). El caserío vasco en el país de las industrias. Ministerio de Agricultura, Pesca y Alimentación, Centro de Publicaciones.

Alberdi, J.C. (2002). Desagrarización del caserío y abandono forestal. Sancho el Sabio, 16, 1130 .

Alberdi, J.C. (2018). Actuar desde la escala local: servicios de ensilado ante el abandono agrario. Espacio, Tiempo y Forma, Serie VI Geografía, 11, 69-98

Altuna, O. (1996). Situación del medio rural del municipio de Usurbil (Unpublished). Oiartzun: Ayuntamiento de Usurbil.

Arrieta E. (2009). Los profesionales agrícolas de la CAV: percepciones urbanas (Unpublished report). Vitoria: IKT.

Baldock, D., Beaufoy, G., Brouwer, F., \& Godeschalk, F. (1996). Farming at the Margins: Abandonment or Redeployment of Agricultural Land in Europe. London: Institute for European Environmental Policy / The Hague.

Blanco, M., Germán, S. G., \& Azcárate, I. B. (2011). El modelo de ayudas directas en la PAC post-2013: análisis de impactos de escenarios potenciales. Economía agraria y recursos naturales, 17(2), 83-108.

Boliari, N. (2013). Land Fragmentation in Bulgaria: Reconsidering Its Measurement and Extent. Review of Europan Studies, 5(1), 99-109

Brocos G. (2015). Diez claves de las ayudas de la nueva PAC. Campo Galego. Retrieved from http://www.campogalego.com/es/desarrollo-rural/diez-claves-de-las-ayudas-de-la-nueva$\mathrm{pac} /$

Cabaña Chávez, C., Benavides Silva, M., \& Pizarro Núñez, N. (2013). CONAF: Su historia y rol en el desarrollo forestal y ambiental de Chile 1972-2013. Santiago de Chile (Chile): Corporación Nacional Forestal.

Caro Baroja, J. (1971). Los vascos. 3rd ed. Madrid: Istmo.

Cingolani, A. M., Noy-Meir, I., Renison, D. D., \& Cabido, M. (2008). La ganadería extensiva: ¿ es compatible con la conservación de la biodiversidad y de los suelos? Ecología austral, 18(3), 253-271. 
Comelles, C. A. (2016, December 21). El impuesto a las viviendas vacías como sanción a la deshabitación. Diario La Ley, (8886), 1.

Corbelle Rico, E., \& Crecente Maseda, R. (2005). Urbanización, forestación y abandono. Cambios recientes en el paisaje de Galicia, 1985-2005. Revista Galega de Economía, 23(1), 35-51.

Corbelle Rico, E., \& Crecente Maseda, R. (2008). El abandono de tierras: concepto teórico y consecuencias. Revista de Economía Gallega, 17(2), 1-15

Delgado, C. (Cord.), Gil de Arriba, C., Hortelano , L. A., \& Plaza , J. I. (2010). La montaña cantábrica oriental. Dinámica socioeconómica, patrimonio ecocultural y desarrollo sostenible. Santander: Eds. Librería Estudio.

Ełxezarreta, M. (1977). El caserío vasco. Bilbao: Fundación C. de Iturriaga y M. de Dañobeitia.

Etxezarreta, M., Cruz, J., Garcia Morilla, M., \& Viladomiu, L. (1995). La agricultura familiar ante las nuevas políticas agrarias comunitarias. Ministerio de Agricultura, Pesca y Alimentación.

Euromontana (1997). L'integration des préoccupations environnementales dans l'agriculture de montagne. Commission Européenne, Direction Générale de L'environnement, Sécurité Nucléaire et Protection Civile.

Ferrer, C., San Miguel, A., \& Olea, L. (2011). Nomenclátor básico de pastos en España. Pastos, $37(1), 7-44$.

García, I. M., \& Rafel, R. M. (2007). El alquiler forzoso de la vivienda desocupada. Indret, 2, 133.

Gómez Orea, D. (1992). Planificación rural. Madrid: Agrícola Española.

Guerrero, L. M. (2001). La entrevista en el método cualitativo (Online document, Facultad de Ciencias Sociales, Universidad de Chile). Retrieved from http://rehue.csociales.uchile.cl/investigacion/genetica/cg04.htm

Guzmán, A. P. (2017). Estrategias de pastoreo para mejorar la sostenibilidad del ovino lechero (Master's thesis, Universitat Politècnica de València, Spain). Retrieved from http://hdl.handle.net/10251/76947

Hatna, E., \& Bakker, M. M. (2011). Abandonment and expansion of arable land in Europe. Ecosystems, 14(5), 720-731.

Hernández Díaz-Ambrona, C. G. (2012). La ganadería extensiva ante la nueva PAC. Asoprovac, $52,8-12$. 
Huber, R., Bugmann, H., Buttler, A., \& Rigling, A. (2013). Sustainable land-use practices in European mountain regions under global change: an integrated research approach. Ecology and Society, 18(3).

Iglesias. M.J. (2010) Medio Rural restringirá al máximo las prejubilaciones ganadera el próximo año. Publicación diaria digital. El diario de Asturias.

Keenleyside, C., Tucker, G., \& Mcconville, A. (2010). Abandono de tierras de cultivo en la UE: una evaluación de tendencias y perspectivas. London: Instituto de Política Medioambiental Europea.

Klare, K., \& Doll, H. (2000). Aus dem Institut für Betriebswirtschaft, Agrarstruktur und Ländliche Räume. Retrieved from https://literatur.thuenen.de/digbib_extern/zi022267.pdf

Llorente, O. (2014). Análisis y valoración del banco de suelo del País Vasco. Gazte Geografía, Lurralde, 1, 53- 71 .

López Iglesias, E. (1996). Movilidad de la tierra y dinámica de las estructuras agrarias en Galicia. Madrid: Ministerio de Agricultura, Pesca y Alimentación, Secretaría General Técnica.

Maceda Rubio, A. (1996). El banco de tierras de Asturias, con especial referencia a su gestión de los programas de cese anticipado de la actividad agraria. Ería, 39-40, 115-142.

Madinabeitia, T. (2001). Lehen sektorea Arrasaten (Unpublished). Arrasateko Udala.

Malagón, E. M. (2012). La Política Agraria Común y las zonas de montaña. leZ: Ingurugiroa eta zuzenbidea. Ambiente y derecho, 10, 13-26.

Mauleon, J. R. (1998). Los cambios de la explotación familiar según el tipo de familia: Explotaciones de leche en el País Vasco. Agricultura y sociedad, 52, 95-117.

Molinero, F., Herrero, D., \& Baraja, E. (2012). Significado y valor de los pagos" PAC" para el estudio de las estructuras agrarias en Castilla y León. Nimbus: Revista de climatología, meteorología y paisaje, 29, 431-46.

Munteanu, C., Kuemmerle, T., Boltiziar, M., Butsic, V., Gimmi, U., Halada, L., ... \& Lieskovský, J. (2014). Forest and agricultural land change in the Carpathian region-a meta-analysis of long-term patterns and drivers of change. Land use policy, 38, 685-697.

Murua Uribetxeberria, A. (2000). Caseríos de Lezo. Gipuzkoa: Ayutamiento de Lezo.

Murua, J. R., Astorkiza, I., \& Eguia, B. (2012). Abandono e infrautilización del suelo agrario en la Cornisa Cantábrica. El caso del País Vasco. Revista Española de Estudios Agrosociales, 231, 6391. 
Osoro Igartua, J. (1997). Caseríos de Elgoibar. Deba Beheko Mendi Nekazaritza Elkartea. Elgoibar (Gipuzkoa).

Porcal Gonzalo, M. C., Galdós, R., \& Ruiz Urrestarazu, E. (2009). Dinámica paisajística de las áreas de montaña del País vasco a través de los cambios en la ocupación del suelo. XXI Congreso de Geógrafos Españoles. Geografía, Territorio y Paisaje: el estado de la cuestión (pp. 13071322). Universidad de Castilla- La Mancha.

Prost, B. (1994). L'agriculture périurbaine: analyse d'une marginalité. Bulletin de L'Association de Géographie Française, 71, 144-151.

Ramos Truchero, G. R. (2009). La sucesión en la ganadería familiar: el ovino de leche en el País Vasco. Eusko Jaurlaritzaren Argitalpen Zerbitzu Nagusia. Servicio Central de Publicaciones del Gobierno Vasco.

Renwick, A., Jansson, T., Verburg, P. H., Revoredo-Giha, C., Britz, W., Gocht, A., \& McCracken, D. (2013). Policy reform and agricultural land abandonment in the EU. Land use policy, 30(1), $446-457$.

Rojo, A., Navarro, J., Del Río, J., \& Gordo, F. J. (2009). Estudio integral de la evolución de las cubiertas vegetales en el TM de San Cebrián de Mazote (Valladolid). Presented at the $5^{\circ}$ Congreso Forestal Español.

Ruiz Urrestarazu, E., \& Galdós, R. (2011). La crisis que no cesa: perspectiva territorial del abandono de las explotaciones agrarias en el País Vasco. Lurralde: Investigación y espacio, 34, 301-313.

Ruiz Urrestarazu, E., \& Galdós, R. (2013a). Actividad agraria y paisaje: la ganadería, clave en la conservación del paisaje vasco-atlántico. Boletín de la Asociación de Geógrafos Españoles, 63, 379-398. http://dx.doi.org/10.21138/bage.1619

Ruiz Urrestarazu, E., \& Galdós, R. (2013b). La pérdida de los espacios agrarios y la artificialización del suelo y forestacion en España y en el Pais Vasco. Lurralde: Investigación y espacio, 36, 121133.

Ruiz Urrestarazu, E., \& Galdós, R. (2005). Reflexiones sobre la desestructuración del caserío vasco. Investigaciones Geográficas, 38, 79-91.

Salvatori, G. (2011). La cooperación en Trentino: un modelo construido a través de 120 años de transformaciones. Euricse (European Research Institute on Cooperative and Social Enterprises). Retrieved from http://euricse.eu/sites/euricse.eu/files/ar2012 en_0.pdf

Uriarte, C. (2015). Situación del medio rural del municipio de Usurbil. Oiartzun: Ayuntamiento de Usurbil Inédito. 
Van den Brink, A. (1990). Structuur in beweging: het landbouwstructuurbeleid in Nederland 1945-1985. Van den Brink S.L

Van der Sluis, T., Pedroli, B., Kristensen, S. B., Cosor, G. L., \& Pavlis, E. (2016). Changing land use intensity in Europe-Recent processes in selected case studies. Land Use Policy, 57, 777-785.

Van Dijk, T., \& Kopeva, D. (2006): Land Banking And Central Europe: Future Relevance, Current Initiatives, Western European Past Experience. Land Use Policy, 26, 286-301

Varela-Redondo, E., Calatrava-Requena, J., Ruiz Urrestarazu-Mirazo, J., Jiménez-Piano, R., \& González-Rebollar, J. L. (2007). Valoración económica del pastoreo en términos de costes evitados en labores de prevención de incendios forestales. Wildfire.

Verburg, P. H., van Berkel, D. B., van Doorn, A. M., van Eupen, M., \& van den Heiligenberg, H. A. (2010). Trajectories of land use change in Europe: a model-based exploration of rural futures. Landscape ecology, 25(2), 217-232.

Zuazagasti, I. (2014). Donostiako sare agroalimentarioa. Behemendi Landa Garapen Elkartea (Unpublished). Oiartzun. 